(though one meningioma occurred synchronously with a pituitary adenoma in a patient not given radiotherapy) and one case of glioma (which was paralleled by a glioma in a contemporaneous patient with Cushing's syndrome who was not given radiotherapy). The apparent disparity between these figures and those of Brada and colleagues emphasises the rarity of these second tumours and the difficulty of interpreting small numbers, particularly in the absence of a control series. Sellar fibrosarcoma, glioma, and meningioma are distinct and disparate pathological processes, each with its own propensity for development under the influence of radiation, and it is probably not justifiable to amalgamate them in an attempt to increase total numbers. Moreover, improvements in diagnostic techniques and accuracy have meant that the rate of pituitary adenoma and meningioma, occurring either together or separately, is difficult to compare with rates in earlier series.

Brada and colleagues' series of 334 patients was selected from 436 patients (102 having been excluded), which may affect its validity. On the basis of their data the authors suggest a guideline of an excess of 2.4 brain tumours in 100 patients so treated and followed up for 20 years. The series at St Bartholomew's Hospital and that of Brada and colleagues are among the largest series of patients receiving megavoltage irradiation for pituitary adenomas to date, and each has taken over 20 years to accrue; the patterns of oncogenesis in even these two large series emphasise that such second brain tumours are rare, and their true incidence could be obtained only from larger experience. On present evidence we consider that the suggested guideline regarding the risks of therapy is unwarranted.

Earlier studies showed clearly that without external beam radiotherapy there is a high rate of recurrence (up to $80 \%$ by 10 years) in patients with macroadenomas after surgery. ${ }^{3}$ Pituitary radiation protects against this most efficiently and remains a valuable treatment for both functioning and nonfunctioning tumours.

J A H WASS G M BESSER A GROSSMAN N PLOWMAN

Departments of Endocrinology and Radiotherapy, St Bartholomew's Hospital,

London ECIA 7BE

T W MEADE

MRC Epidemiology and Medical Care Unit,

Northwick Park Hospital,

Harrow,

Middlesex HAl 3UJ

1 Brada M, Ford D, Ashley S, Bliss JM, Crowley S, Mason M, et al. Risk of second brain tumour after conservative surgery and Risk of second brain tumour after conservative surgery and (23 May.)

2 Jones A. Radiation oncogenesis in relation to the treatment of pituitary tumours. Clin Endocrinol 1991;35:379-97.

3 Sheline GE. Role of conventional radiation therapy in treatmen of functional pituitary tumours. In: Linfoot JA, ed. Recen advances in the diagnosis and treatment of pituitary tumours. New York: Raven Press, 1979;289-313.

\section{Growth hormone and recurrence of tumour}

EDITOR,-A L Ogilvy-Stuart and colleagues report their study of whether giving growth hormone to children with growth hormone insufficiency after cranial irradiation for brain tumours or leukaemia causes recurrence of tumour. ${ }^{\prime}$ Encouraging though it was, we are cautious about accepting the conclusion that growth hormone did not increase the risk of recurrence.

The strength of articles such as this centres on the calculation of the study's statistical power, but this was not considered. We find this surprising considering recent articles in the $B M \mathcal{F}$ about this important aspect of a study's design. ${ }^{2}$ Small study groups will almost certainly lead to a negative result.

In Ogilvy-Stuart and colleagues' paper 15 (35\%) of the 43 children with medulloblastoma who did not receive growth hormone relapsed. For $85 \%$ power and with a $5 \%$ significance on a change in relapse rate from $35 \%$ to $50 \%$ roughly 300 subjects in each group would be required. The message is clear: large, multicentre collaborative follow up programmes are required to clarify this important issue.

PETER HINDMARSH C G D BROOK

Endocrine Unit,

Middlesex Hospital

London WIN 8AA

1 Ogilvy-Stuart AL, Ryder WDJ, Gattamaneni HR, Clayton PE, 1992;304:1601-5. (20 June.)

2 Altman DG. Statistics and ethics in medical research. III. How large a sample? BMF 1980;281:1336-8.

\section{Medical reports for courts}

EDITOR, - I was disappointed to read that there is no valid method for distinguishing psychogenic back pain from organic pain or malingering. ${ }^{1}$ One of the sadder aspects of psychiatric practice is treating patients who are attempting to obtain compensation. Two distressing aspects are the time the cases take to reach a settlement and the need for psychiatric examination by doctors whom the patients perceive as being paid by the insurance company to prove that they are malingering, and who sometimes treat the patients with contempt. I am sure that these bitter experiences and the anger they arouse exacerbate the clinical condition.

I suggest that psychiatric reports in these cases should be requested and paid for by the court; in fact, possibly all medical reports presented to a court should be requested and paid for by that court. This would put an end to the curren situation, in which a patient is forced into a professional relationship with a doctor who is being paid by someone with whom the patient is in civil dispute; this is often degrading for the patient, if not for all concerned.

Plumpton,

J S PRICE

East Sussex BN7 3AN

1 Jayson MIV. Trauma, back pain, malingering, and compensation. BMJ 1992;305:7-8. (4 July.)

\section{ABO blood group and gall stone disease}

EDIToR,-Tatu Juvonen and Onni Niemelä did not find any association between $\mathrm{ABO}$ blood group and symptomatic gall stone disease in a study of 171 patients attending one hospital for cholecystectomy. 'The Oxford record linkage study includes statistical information on the hospital care of a large, geographically defined population. The patients' ABO blood groups are recorded when available. The data on ABO blood groups and disease from 1968 to 1978 have been tabulated (that is, for all records coded to the eighth revision of the ICD). ${ }^{2}$ Work is in progress to cover more Shalet SM. Growth hormone and tumour recurrence. $B M \mathcal{J}$

recent years. Blood group was recorded for 7862 $(53 \%)$ cases of gall bladder disease (ICD (eighth revision) 574-576) admitted from 1968 to 1978.

The table shows the distribution of blood group in these patients compared with all hospital inpatients for whom blood group was recorded. Blood group A was slightly more common in the patients admitted with gall bladder disease than in the general inpatient population. The approximate relative risk of gall bladder disease in patients with blood group A compared with group $\mathrm{O}$ was 1.04 ( $95 \%$ confidence interval 1.00 to 1.09 ), the increased risk not reaching significance even with this fairly large number of cases $(p=0 \cdot 07)$.

Further information is available from a review of 21 published studies of blood group and cholelithiasis, with a total of 14660 cases from different geographical locations. ${ }^{3}$ The pooled data from these studies show that blood group A was more common (relative to group $\mathrm{O}$ ) in patients with cholelithiasis than in the general population, with a relative incidence of $1 \cdot 15(\mathrm{p}<0.001)$.

These data give some support to the hypothesis that ABO blood group is a marker for the risk of developing gall stones, but the relative risks are small. In Oxford the data are less likely to be confounded by geographical factors than they are in the pooled review, and there may be geographical differences in the association between blood group and disease. Calculation of the population attributable risk fraction ${ }^{4}$ suggests that this association (whatever its mechanism may be) accounts for only $2 \%$ or $6 \%$ of the total risk of developing gall stones, depending on whether 1.04 or $1 \cdot 15$ is taken as the best estimate of relative risk.

JOHN NEWTON MICHAEL GOLDACRE

Unit of Health-Care Epidemiology,

Department of Public Health and Primary Care,

Oxford University,

Oxford OX3 7LF

1 Juvonen T, Niemela $\mathrm{O}$. ABO blood group and gall stone disease. $B M J$ 1992;305:26-7. (4 July.)

2 Goldacre M, Griffith M. ABO blood group and disease in Oxford 1968-1978. Oxford: Unit of Clinical Epidemiology, Oxford University, 1989

3 Mourant AE, Kopec AC, Domaniewska-Sobczak K. Blood groups and diseases: a study of associations of diseases with blood groups and diseases: a study of associations of diseases with bloot groups and
Press, 1978 .

4 Hennekens CH, Buring JE. Epidemiology in medicine. Boston Little, Brown, 1987.

\section{Videotaped interviews with children suspected of being sexually abused}

EDITOR,-Richard Harrington raises several points ${ }^{\prime}$ about the methods of our study about professionals' ratings of videotapes of interviews of children evaluated for suspected sexual abuse. ${ }^{2} \mathrm{We}$ agree that our selection of professionals who were interested in participating in the project may have maximised their levels of agreement.

Although we reported the number of raters in each group who agreed with the consensus ratings, we also calculated (but did not include in the report) the $x$ statistic for each professional group. This statistic, which varies from 1.0 (perfect agreement) to $-1 \cdot 0$ (perfect disagreement), takes into account agreement expected by chance alone. As the table shows, $x$ ranged from 0.821 for police

Distribution of $A B O$ blood group in patients with gall bladder disease compared with all inpatients (figures are numbers (percentages))

\begin{tabular}{|c|c|c|c|c|c|}
\hline & \multicolumn{4}{|c|}{ Blood group } & \multirow[b]{2}{*}{ Total } \\
\hline & A & $\mathrm{AB}$ & $\mathrm{O}$ & B & \\
\hline $\begin{array}{l}\text { Gall bladder disease } \\
\text { All inpatients }\end{array}$ & $\begin{array}{r}3525(44 \cdot 8) \\
72462(43 \cdot 5)\end{array}$ & $\begin{array}{r}233(3 \cdot 0) \\
5202(3 \cdot 1)\end{array}$ & $\begin{array}{r}3468(44 \cdot 1) \\
74400(44 \cdot 7)\end{array}$ & $\begin{array}{r}636(8 \cdot 1) \\
14501(8 \cdot 7)\end{array}$ & $\begin{array}{r}7862(100 \cdot 0) \\
166565(100 \cdot 0)\end{array}$ \\
\hline
\end{tabular}

